\title{
Transfer of Peptostreptococcus elsdenii Gutierrez et al. to a New Genus, Megasphaera [M. elsdenii (Gutierrez et al.) comb. nov.]
}

\author{
MORRISON ROGOSA \\ Laboratory of Microbiology and Immunology, National Institute of Dental Research, \\ Bethesda, Maryland 20014
}

\begin{abstract}
Peptostreptococcus elsdenii Gutierrez et al. 1959 does not have the characteristics of the genus Peptostreptococcus Kluyver and van Niel. The organism appears to be unique and is here relegated to a new genus, Megasphaera. The type species is Megasphaera elsdenii (Gutierrez et al.) comb. nov., of which the type strain is LC1 (= ATCC $25940=$ NCIB 8927). The placement of this genus in a family will be done in a future publication.
\end{abstract}

Kluyver and van Niel (6) named and described a new genus, Peptostreptococcus, stating that the organisms in the genus were proteolytic or were capable of fermenting proteindecomposition products and were grampositive. Organism LC [Elsden and Lewis (2), Elsden et al. (3)], isolated from the rumen of sheep and cattle, was subsequently named Peptostreptococcus elsdenii by Gutierrez et al. (4). However, the cell wall composition and serological characteristics (1) of organism LC are different from those of the gas- and foul odor-producing organisms which possess the general characteristics of the type species of Peptostreptococcus. Organism LC is also different from these and all other organisms of the genus Peptostreptococcus in being gramnegative by direct staining techniques; electron microscopy (Fig. 1) confirms that the outer cell wall of the organism described by Elsden $(2,3)$ has an anatomy of the gram-negative type.

As a matter of fact, Gutierrez et al. (4) really recognized the gram-negative nature of organism LC despite their attempts to cite equivocal gram results in heavy smears, in rumen contents containing particulate matter, etc. Their final statement of justification for $P$. elsdenii as a new species begins as follows: "Although the strains are predominantly Gram negative...." Therefore the name Peptostreptococcus elsdenii Gutierrez et al. (4) is inappropriate because the organism referred to by this name does not have the characteristics of Peptostreptococcus as originally defined (6) and differs significantly from the type species of Peptostreptococcus. The organism of Elsden et al. $(2,3)$ and related strains appear different from those belonging to other known genera. Indeed, Elsden et al. (3) recognized this when they stated, "The possibility that it is a member of a new genus cannot be dismissed." But for a variety of reasons, including the fact that the number of known strains was then limited both in number and in source, they preferred to delay proposing a new name, as follows: "We propose for the time being, therefore, to refer to it as rumen organism LC."

Since then, however, a significant number of additional strains have been isolated and studied from bovine and ovine rumen in widely differing locations in the United States and in England.

In consideration of the foregoing, it is here proposed that these organisms belong to a new genus, as follows:

Megasphaera gen. nov.

Me.ga.sphae'ra. Gr. adj. megas, megale, mega big; Gr. noun sphaera a sphere; M.L. fem. n. Megasphaera big sphere.

Cocci in pairs; occasionally the unit diplococci are arranged to give the appearance of chains. Cells are relatively large, approaching a diameter of about $2 \mu \mathrm{m}$ or more. Nonmotile and nonsporing. Gram-negative. Obligately anaerobic. Complex nutritional requirements. Chemoheterotrophic. Gas produced. Lactate and glucose are fermented with the production of lower fatty acids, $\mathrm{CO}_{2}$, and some $\mathrm{H}_{2}$. Unlike Veillonella, succinate, fumarate, and malate are not attacked, and propionate is not produced 


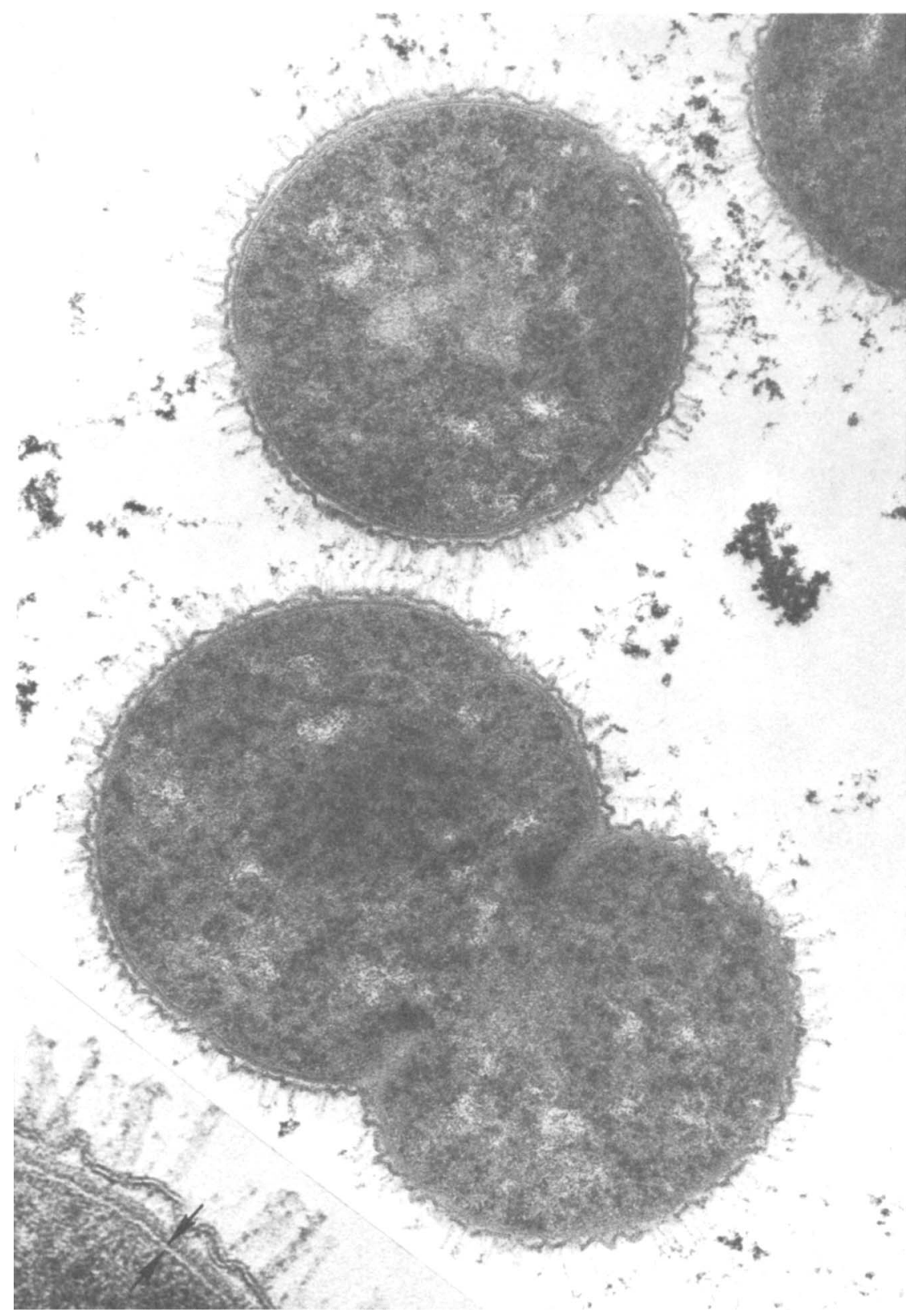

Fig. 1. Electron micrograph of a thin section of the type strain (ATCC 25940) of Megasphaera elsdenii $\times 46,000$. Inset shows details of wall and surface; $\times 138,000$. Note coccal shape, size (1.2 to $1.9 \mu \mathrm{m})$, and gram-negative type (triple-layered) outer wall bearing $a$ "nap" of filaments. The cytoplasmic membrane (between arrows, inset) is separated from outer wall by a middle wall layer. Strain B159 (ATCC 17752), whose cell wall composition was previously studied by Bahn et al. (1), has a morphology indistinguishable from that of ATCC 25940 shown here; strain T81 (ATCC 17753) has a very similar gram-negative morphology except that the "nap" of filaments has not been demonstrated. Fixation by $2.5 \%$ glutaraldehyde (10) followed by $1 \%$ osmium tetroxide and uranyl acetate treatment (9). Embedment in Epon 812 (7). Sections stained with lead citrate (8). 
from succinate but by an acrylate pathway as in Clostridium propionicum (5).

The placement of this genus in a family will be attended to in a future publication to appear in this Journal.

The type species is Megasphaera elsdenii (Gutierrez et al.) comb. nov. It has been described under the names "Organism LC" by Elsden et al. (3) and Peptostreptococcus elsdenii by Gutierrez et al. (4) and has the characteristics of the genus as given above. $M$. elsdenii has been isolated from the rumen of cattle and sheep; probable habitat is the rumen of Ruminantia (soluble starch and $5 \% \quad \mathrm{CO}_{2}$ facilitate isolation).

The type strain is ATCC 25940 (= NCIB 8927); this strain, LC1 [Elsden et al. (3)], was isolated from the rumen of a sheep. Its description is documented by Elsden et al. (3); this description has been confirmed and up-dated by the present author as follows.

In wet mounts, cells appear spherical with dimensions of 2.4 to $2.6 \mu \mathrm{m}$, whereas in stained or fixed preparations adjacent sides of diplococci tend to be flattened, and the diameter ranges from 1.2 to $1.9 \mu \mathrm{m}$. Occasionally 8 - to 10-unit diplococci are arranged so as to give the appearance of a chain. Thin smears are gramnegative even in 4-hr cultures. Grows well in a $0.4 \%$ yeast extract medium containing $0.05 \%$ $\mathrm{KH}_{2} \mathrm{PO}_{4}, 0.05 \% \mathrm{NH}_{4} \mathrm{Cl}, 0.03 \% \mathrm{MgCl}_{2} \cdot 6 \mathrm{H}_{2} \mathrm{O}$, $0.03 \%$ thioglycolic acid, $2 \%$ soluble starch, and $1.3 \%$ D L-sodium lactate at $p \mathrm{H} 7.4$ and $38 \mathrm{C}$. Growth occurs from 25 to $40 \mathrm{C}$ but not at $45 \mathrm{C}$. Cultures stored at $4 \mathrm{C}$ must be transferred at least fortnightly; may not survive a number of freeze-drying procedures; survives in liquid nitrogen. Surface colonies after 4 days are 0.5 to $2.0 \mathrm{~mm}$ in diameter, slightly raised, circular, and entire, and the surface is glistening to slightly rough and adherent to butyrous. Deep colonies are thin and disc-shaped, up to $4 \mathrm{~mm}$ in diameter and greenish-yellow or honeycolored. Catalase and indole negative; gelatin not liquefied; nitrate not reduced; $\mathrm{H}_{2} \mathrm{~S}$ produced. In a medium containing $0.4 \%$ yeast extract, $0.03 \%$ thioglycolic acid, and $1 \%$ substrate $(p \mathrm{H} \mathrm{7.4)}$ and in an atmosphere of $95 \%$ $\mathrm{H}_{2}+5 \% \quad \mathrm{CO}_{2}$ at 35 to $38 \mathrm{C}$, there is good growth and gas production with lactate, glucose, and fructose; there is variable growth and fermentation with maltose, sorbitol, and mannitol; there is no growth and no fermentation with arabinose, cellobiose, dextrin, esculin, galactose, glycerol, inulin, lactose, mannose, raffinose, rhamnose, salicin, starch, sucrose, trehalose, or xylose. Final $p \mathrm{H}$ on glucose or fructose is 4.0 to 5.0 ; on lactate, 7.8 to 8.0 . Products from lactate are acetate, propionate, $\mathrm{C}_{4}$ straight and branched acids, valerate, little or no caproic acid, a large quantity of $\mathrm{CO}_{2}$, and small amounts of $\mathrm{H}_{2}$. Products from glucose are different from those from lactate in that some formate is produced, less acetate, propionate, butyrate, and valerate are formed, and caproate (about $60 \%$ or more) is the most copious product.

Some strains other than the type strain have fermented glycerol or sucrose and have grown at $45 \mathrm{C}$ but not at $50 \mathrm{C}$.

\section{ACKNOWLEDGMENT}

I am greatly indebted to Roger M. Cole for the preparative procedures, the electron microscopy, and the photograph which is shown herein.

\section{LITERATURE CITED}

1. Bahn, A. N., P. C. Y. Kung, and J. A. Hayashi. 1966. Chemical composition and serological analysis of the cell wall of Peptostreptococcus. J. Bacteriol. 91:1672-1676.

2. Elsden, S. R., and D. Lewis. 1953. The production of fatty acids by a gram-negative coccus. Biochem. J. 55:183-189.

3. Elsden, S. R., B. E. Volcani, F. M. C. Gilchrist, and D. Lewis. 1956. Properties of a fatty acid forming organism isolated from the rumen of sheep. J. Bacteriol. 72:681-689.

4. Gutierrez, J., R. E. Davis, I. L. Lindahl, and E. J. Warwick. 1959. Bacterial changes in the rumen during the onset of feed-lot bloat of cattle and characteristics of Peptostreptococcus elsdenii n. sp. Appl. Microbiol. 7:16-22.

5. Johns, A. T. 1952. The mechanism of propionic acid by Clostridium propionicum. J. Gen. Microbiol. 6:123-127.

6. Kluyver, A. J., and C. B. van Niel. 1936. Prospects for a natural system of classification of bacteria. Zentralbl. Bakteriol. Parisitenk. Abt. II 94:369-403.

7. Luft, J. H. 1961. Improvements in epoxy resin embedding methods. J. Biophys. Biochem. Cytol. 9:409-414.

8. Reynolds, E. S. 1963. The use of lead citrate at high $\mathrm{pH}$ as an electron-opaque stain in electron microscopy. J. Cell Biol. 17:208-212.

9. Ryter, A., and E. Kellenberger. 1958. L'inclusion au polyester pour l'ultramicrotomie. J. Ultrastruct. Res. 2:200-214.

10. Sabatini, D. D., K. Bensch, and R. J. Barnett. 1963. Cytochemistry and electron microscopy. The preservation of cellular ultrastructure and enzymatic activity by aldehyde fixation. J. Cell Biol. 17:19-58. 